\title{
The Overexpression of The VvWRKY2 Transcription Factor in Potato Improved the Agricultural Performance and Tubers' Physio-Chemical and Industrial Properties Even Under Non-Stress Conditions
}

Nour Chiab ( $\nabla$ nour.chiab@enis.tn )

Ecole Nationale d'Ingénieurs de Sfax: Ecole Nationale d'Ingenieurs de Sfax mariam kammoun

National Engineering School of Sfax: Ecole Nationale d'Ingenieurs de Sfax mariam charfeddine

Ecole Nationale d'Ingénieurs de Sfax: Ecole Nationale d'Ingenieurs de Sfax rim mzid

CBBC: Centre de Biotechnologie de Borj Cedria

radhia gargouri-bouzid

ENIS: Ecole Nationale d'Ingenieurs de Sfax

\section{Research Article}

Keywords: Field, Greenhouse, Potato, Transcription factors, WRKY.

Posted Date: April 1st, 2021

DOI: https://doi.org/10.21203/rs.3.rs-361740/v1

License: (a) This work is licensed under a Creative Commons Attribution 4.0 International License. Read Full License 


\section{Abstract}

The tryptophan-arginine-lysine-tyrosine (WRKY) transcription factors play important roles in plant growth and response to biotic and abiotic stresses. Several studies described WRKY factors overexpression in different plant species. In a number of cases, modification in morphology and seed size were described in transgenic plants overexpressing transcription factors from this family. In this work, we aimed to study the effect of a grapevine $V v W R K Y 2$ transcription factor on transgenic potato plants growth, yields and chemical properties of tubers produced out of any stress condition in the greenhouse and in the field. The results were compared with the wild type commercial variety "Belle de Fontenay" (WT). Data showed that the overexpression of the $V_{v} W R K Y 2$ transcription factor increased significantly the leaf area and stem diameter of transgenic plants in comparison to WT. A modification of leaf shape was also noticed in VVWRKY 2 overexpressing potato plants. The tuber yield, caliber, dry matter, starch and mineral content of transgenic tubers was higher than WT, while soluble sugars level decreased. All these results suggest that the $V V W R K Y 2$ overexpression in potato plants seems to have positive effect on plant vigor, yield and tuber quality under normal conditions in addition to its positive effect on plant response to stresses.

\section{Introduction}

Potato (Solanum tuberosum L.) is the world's leading non-cereal food (FAO 2019). It is considered as an important crop for food security since it is a valuable source of nutrients for the human diet (Beals 2019). However, the global potato yield is negatively affected by several biotic and abiotic constraints limiting the plant growth and production (Dahal et al. 2019; FAO 2019). Improving crop tolerance to stress needs a better comprehension of plant mechanisms to perceive and respond the external signals (Tuteja 2007; Qin et al. 2015). Stress activates several plant responses which include changes in gene expression patterns regulated by complex signal transduction pathways (Shinozaki et al. 2015). Transcription factors (TFs) play crucial roles in signaling pathways involved in biotic and abiotic stress responses (Yan et al. 2015; Li et al. 2016; Guo et al. 2019). Genome-wide analyses of TF encoding genes revealed that they correspond to $20 \%$ of plant genome (lida et al. 2005; Xiong et al. 2005). These factors are important regulators of transcription of plant defense genes (Asai et al. 2002; Singh et al. 2002; Qiu et al. 2007; Guo et al. 2019; Li, Nayar, et al. 2020). The WRKY TF group is the most studied TF family involved in plant stress responses. The WRKY proteins belong to a unique TF superfamily of higher plants and algae which plays important roles in multiple pathways involved in response to biotic and abiotic stresses ( $\mathrm{Li}$, Zhang, et al. 2020). Many members of the WRKY TF family have been identified in different plant species (Rushton et al. 2010; Ayadi et al. 2016, 2019; Li, Zhang, et al. 2020). They are characterized by N-terminal DNA binding domain based on invariable heptapeptide sequence WRKYGQK and a C-terminal zinc finger structure (Eulgem et al. 2000). These proteins are classified into 3 groups according to the number of WRKY domains and the structure of the zinc finger motif (Ulker and Somssich 2004). The WRKY TF participate in a variety of plant reactions such as senescence, embryogenesis, seed coat and trichome development, regulation of hormone biosynthesis, sugar and hormonal signaling (Ayadi et al. 2016; Finatto et al. 2018; Chen et al. 2019; Li, Zhang, et al. 2020), in addition to response to abiotic stresses 
such as drought and salinity (Chen et al. 2012), and ABA (Zou et al. 2004; Xie et al. 2005). They also play important roles in the regulation of plant growth and development (Ayadi et al. 2019; Chen et al. 2019).

Mzid et al. (2007) and Marchive et al. (2007) identified two genes encoding WRKY TFs in grapevine (Vitis vinifera). The overexpression of $V_{v} W R K Y 1$ and $V_{v} W R K Y 2$ factors in transgenic tobacco plants led to plant resistance to phytopathogens. More recently, Mzid et al. (2018) reported that transgenic tobacco plants, overexpressing $V v W R K Y 2$ TF displayed higher tolerance to salinity when compared to WT.

In the present study, we overexpressed the VVWRKY2TF in potato plants and evaluated the agnomical, physiological and morphological performances of transgenic potato plants out of any stress conditions. Both WT and $V v W R K Y 2$ overexpressing plants were grown in greenhouse and field in the absence of any constraints in order to study the effect of the overexpression of the VVWRKY2TF on the agricultural performance and plant growth and physiology.

\section{Materials And Methods}

\subsection{Production and selection of transgenic $V v W R K Y 2$ potato lines}

A French potato cultivar (Belle de Fontenay, BF15) was used to produce transgenic potato plants. The $V v W R K Y 2$ CDNA was inserted into the MDC32 vector flanked between the Pr35S promoter and terminator (Mzid et al. 2007). The Agrobacterium tumefaciens LBGV3010 strain harboring the MDC32:: VvWRKY2 plasmid were used for potato transformation as described by Gargouri-Bouzid et al. (2005). Stems and leaves were used for transformation and plant regeneration was performed in a regeneration medium corresponding to MS basal medium (Murashige and Skoog 1962) supplemented with Morel vitamins (Morel and Wetmore 1951) and containing sucrose $20 \mathrm{~g} \mathrm{I}^{-1}$, phytagel $4 \mathrm{~g} \mathrm{I}^{-1}$ and indole-3-acetic acid (IAA) $0.05 \mathrm{mg} \mathrm{l}^{-1}$, Zeatin $3 \mathrm{mg} \mathrm{l}^{-1}$ and GA3 $3 \mathrm{mg} \mathrm{l}^{-1}$ and antibiotics (Hygromycin $3 \mathrm{\mu g} \mathrm{ml}^{-1}$ and cefotaxime 250 $\mu \mathrm{g} \mathrm{ml}^{-1}$ ). The culture was performed at $24^{\circ} \mathrm{C}$ in a culture room with a $16 / 8$ hours day/night alternation. The explants were transplanted every two weeks until production of adventive buds. The transgenic plants were multiplied in MS medium that contains $3 \mathrm{\mu g} \mathrm{ml}^{-1}$ Hygromycin. Plants rooted in this medium were selected for further analysis.

\subsection{Plant DNA and RNA analyses}

Genomic DNA as extracted from potato plants grown on hygromycin-supplemented MS medium as described by Dellaporta et al. (1983). The PCR reaction was performed by using $V v W R K Y 2$ and $35 S$ promoter specific primers. $V v W R K Y 2$ forward primer: 5'-AAGTAATATTGATCAATGGCTGAA-3', VvWRKY2 reverse primer: 5'-GATATTCTTTTCAACAAAGG-3'. 35S forward primer: 5'-GATATTCTTTTCAACAAAGG-3', 35S reverse primer: 5'-TCCTCTCCAAATGAAATGAA-3'. The PCR program used was the following: Initial denaturation at $94^{\circ} \mathrm{C}$ for 5 min, followed by 40 amplification cycles: Denaturation 1 min at $94^{\circ} \mathrm{C}$, hybridization at the hybridization temperature of each pair of primer, and final extension $1 \mathrm{~min}$ at $72^{\circ} \mathrm{C}$. The transcription of the $V V W R K Y 2$ transgene was verified by RT-PCR analysis on total RNA extracted as described by Verwoerd et al. (1989) and modified by Saïdi et al. (2009). The extracted RNA was used as 
template for cDNA synthesis by the reverse transcriptase MoMLV (Bio Basic Inc) using an Oligo-dT as primer. The obtained cDNA, was used for the PCR amplification reaction using the $V_{v} W R K Y 2$ gene specific primers. The PCR and RT-PCR products were separated by electrophoresis on a $1 \%$ agarose gel.

\subsection{Greenhouse and field culture conditions}

Vitro-plants from one transgenic potato line overexpressing the $V_{V} W R K Y 2 \mathrm{TF}$ and WT plants were used in this experiment. These plants were micro-propagated by node culture according to Nozeran and Rossignol-Bancilhon (1977) in liquid MS medium enriched with vitamins (Morel and Wetmore 1951). The culture was carried out in a culture chamber at $24^{\circ} \mathrm{C}$ and a photoperiod of $13 / 11 \mathrm{~h}$ light/dark cycle with light intensity of $250 \mu \mathrm{mol} \mathrm{m} \mathrm{m}^{-2} \mathrm{~S}^{-1}$. Two-weeks-old in vitro, plants that have developed roots in liquid MS medium were transferred into plastic pots of $10 \mathrm{~cm}$ diameter. These pots contained a mix $(\mathrm{v} / \mathrm{v})$ of soil and fertilizer (Potgrond H: Klasmann Deilmann, Geeste, Germany) and were put in a greenhouse (Temperature between 14 to $25^{\circ} \mathrm{C}$ ). The plants were irrigated with tap water every 2 days. After 75 days, the minitubers were harvested and stored at $4^{\circ} \mathrm{C}$ in the dark for further analysis and they were used as seeds for subsequent field culture. At the end of dormancy period, minitubers were transferred into a dark chamber at $25^{\circ} \mathrm{C}$. One month later, minitubers that have developed sprouts were planted in the field (from December 2018 to February 2019) in Sfax, Tunisia. The field preparation involved soil fertilization using a local fertilizer (Biocompost Elbosten), row preparation, seed minitubers spacing, and weed control were applied. The average temperature and humidity of field culture were around $13^{\circ} \mathrm{C}$ and $59 \%$ respectively (timeanddate.com). During the culture period, the plants were irrigated with tap water once a week. Tuber harvesting was performed after 75 days of field culture.

\subsection{Sampling and analysis of growth parameters}

During the culture periods in both greenhouse and field, measurements of growth parameters were conducted in triplicates every 10 days. Plant height was measured using a steel ruler, the diameter of the stem was assessed $2 \mathrm{~cm}$ above the ground, and the number of compound leaves was noted for both WT and the $V v W R K Y 2$ overexpressing plants. Leaf area and stomatal conductance of three upper leaves from the WT and the transgenic plants were measured after 30 and 60 days of greenhouse and field cultures using the methods of Pandey and Singh (2011) and a promoter from Decagon Devices Model SC-1 respectively.

\subsection{Determination of chlorophyll content}

The leaf chlorophyll content was determined according to the method of Arnon (1949). Fresh leaves $(0.01 \mathrm{~g})$ were ground in a mortar with $500 \mu \mathrm{l}$ of pure acetone and $1 \mathrm{ml}$ of $80 \%$ acetone. The supernatant containing the chlorophyll pigments was obtained after centrifugation at $12000 \mathrm{rpm}$ for $15 \mathrm{~min}$ and was adjusted to $2 \mathrm{ml}$ with $80 \%$ acetone. The optical density was then measured at $645 \mathrm{~nm}$ and $663 \mathrm{~nm}$. The chlorophyll (a) and (b) contents were calculated using the following formulae:

$\operatorname{Chl}(a)=(12.7 * A 663-2.69 * A 645) * V / F w ; C h l(b)=(22.9 * A 645-4.68 * A 663) * V / F w$ 
The total chlorophyll= $\mathrm{Chl}(\mathrm{a})+\mathrm{Chl}(\mathrm{b})$

Where V: volume of sample and Fw: Fresh weight of leaves

\subsection{Determination of tuber's yield, caliber, eyes number and color}

After 75 days of greenhouse and field culture, the WT and transgenic potato tubers were harvested, counted and weighed to determine their average number and weight in the different culture conditions. Calibers and number of eyes per tuber were also determined. The skin color of tubers was measured using a Chroma Meter CR-400/410 colorimeter (Konica Minolta). By scanning the potato skin at five locations, three orthogonal coordinates define these parameters: the clarity index $L^{*}$, the chromatic coordinates $a *$ (red) and b* (yellow).

\subsection{Determination of the tuber's chemical composition}

The percentage of dry matter was determined after drying three fresh samples at $105^{\circ} \mathrm{C}$ for 48 hours until constant weight (AFNOR 1982) and calculated using the following formulae: Dry matter $=(D W / F W) * 100$, where FW is the fresh weight and DW is the dry weight. The ash content (\%) was determined by incineration of the dry matter in a muffle furnace for 4 hours at $550^{\circ} \mathrm{C}$ (AFNOR, 1982). The determination of the reducing sugar content was carried out according to the method of Miller (1959). The reducing sugars of the sample are recovered in the supernatant and then assayed by dinitro-salicylic acid (DNS). The optical density is then determined at $550 \mathrm{~nm}$ and the content of reducing sugars is determined based

on a standard curve of glucose. The lipid content of potato tubers was analyzed according to Rogan et al. (2000). The starch content was determined using the enzymatic colorimetric method described by Khabou et al. (1996).

\section{Statistical Analysis}

All the experiments were performed using three independent biological replicates and the data were presented on average \pm the standard deviation (SD). Results were subjected to the ANOVA test and compared by the Newman-Keuls test using the statistical software GraphPad Prism 8 (2019 version). Comparisons with $P<0.05$ were considered significantly different.

\section{Results}

Transgenic potato plants overexpressing the $V v W R K Y 2 T F$ were produced. To investigate whether the $V V W R K Y 2$ overexpression could have an effect on the agricultural performance of transgenic plants we performed a greenhouse and field culture of potato plants overexpressing the $V_{v} W R K Y 2 \mathrm{TF}$.

\subsection{Production of transgenic potato line overexpressing the VvWRKY2 TF}

A recombinant $A$. tumefaciens strains harboring the $V v W R K Y 2$ cDNA inserted in the MDC32 vector (Mzid et al. 2007), was used for potato leaf and stem transformation. The $V_{V} W R K Y 2$ cDNA is flanked by the 
Cauliflower Mosaic virus (CaMV) 35S RNA promoter and terminator. Transgenic potato plant regeneration was performed in hygromycin supplemented medium, and rooted plantlets were multiplied by in vitro node culture. The presence of the $V v W R K Y 2$ transgene was verified by PCR analysis on total plant DNA using the CaMV35S promoter specific primers leading to the amplification of a 300 bp fragment (Fig. 1a). It was further confirmed by the amplification of a $1.6 \mathrm{kbp}$ DNA fragment of the $V_{v} W R K Y 2 \mathrm{cDNA}$ (Fig. 1b). $V v W R K Y 2$ expression was assessed by RT-PCR using the total RNA extracted from the $V v W R K Y 2$ plant leaves (Fig. 1c).

\subsection{VvWRKY2 overexpression in potato promotes plant growth parameters}

One transgenic potato line overexpressing the $V v W R K Y 2 T F$ was used in this study. The effect of the overexpression of $V v W R K Y 2$ on potato plant growth was assessed both in the greenhouse and field culture conditions. The plant height and compound leaves number measured during the culture period didn't show any significant difference between the VvWRKY2 transgenic plants and WT in both culture conditions (Fig. 2). However, the VvWRKY2 transgenic plants exhibited higher stem diameter and leaf area in comparison to WT plants (Fig. 3). The $V v W R K Y 2$ overexpressing plants exhibited a distinct foliar shape and displayed longer leaf petioles compared to the WT leaves both in greenhouse and field culture conditions (Fig. 4). Moreover, the VVWRKY2 transgenic potato plants displayed significantly higher stomatal conductance than the WT in both culture conditions (Fig. 5a).

\subsection{The VvWRKY2 overexpression in potato did not change the leaves chlorophyll content}

The evaluation of the chlorophyll content of the WT and $V V W R K Y 2$ overexpressing potato plants did not show any significant difference (Fig. 5b).

\subsection{The VVWRKY2 overexpression in potato increased tubers yield and caliber and modified tubers' color}

The potato plant yields were determined to evaluate the tuber number and weight per plant (Table1). Accordingly, we found that the $V v W R K Y 2$ transgenic plants cultivated in the greenhouse produced a higher number of tubers than WT. In contrast, under field conditions WT plants produced more tubers than $V_{v} W R K Y 2$ transgenic plants. The tuber weight per plant was significantly higher for $V v W R K Y 2$ transgenic plants than WT in both culture conditions. Similarly, the tubers of $V_{v} W R K Y 2$ transgenic plants from greenhouse and field cultures showed larger caliber (based on tuber length) and higher number of eyes than the WT (Table1). Interestingly, a clear difference of the skin color was noticed between the $V_{v} W R K Y 2$ and WT tubers (Fig. 6). The tubers from the $V_{v} W R K Y 2$ transgenic plants showed lighter yellow color index and higher clarity than WT.

\subsection{The VVWRKY2 overexpression in potato improved the nutritional qualities of tubers}

Our results showed that the tubers of the $V_{V} W R K Y 2$ transgenic plants showed higher dry matter, ash, starch and mineral content such as potassium, magnesium, and calcium in comparison to WT. In contrast, higher levels of lipids and reducing sugars were measured in the WT in comparison to the VvWRKY2 overexpressing tubers (Table2). 


\section{Discussion}

Potato is an important food crop in the world, occupying the fourth rank after wheat, rice, and corn (Zhu et al. 2020). However, because of its high sensitivity, biotic and abiotic constraints limit the productivity of this plant (Chacón-Cerdas et al. 2020). Most research topics focus on the generation of new diseases resistant varieties and with the capacity to produce tubers of good quality in extreme climate conditions (Ghislain and Douches 2020). WRKY TFs have been extensively explored in various model plants (Bai et al. 2018; Guo et al. 2019; Chen et al. 2019; Li, Zhang, et al. 2020). This TF family is involved in diverse processes in response to biotic and abiotic stresses as well as in plant development and physiology (Phukan et al. 2016; Jiang et al. 2017; Bai et al. 2018; Finatto et al. 2018; Yao et al. 2020). In this study, we focused on the effect of the overexpression of $V v W R K Y 2 T F$ in potato plants. The plant growth was assessed both in the greenhouse and field culture conditions. In fact, the knowledge of field performance is very important for an accurate evaluation of genetically modified plants' effect on yield and safety analysis (Agarwal et al. 2017). Our data showed that the overexpression of the $V_{v} W R K Y 2$ TF did not modify the height of plants in comparison to WT both in greenhouse and in field. These data are in agreement with those of Zhu et al. (2018) who found that under standard conditions, the VvWRKY3O overexpressing Arabidopsis plants showed the same growth as the WT. Similarly, the meta-analysis of the effect of overexpression of WRKY TF on plants made by Guo et al. (2019) reported that there was no significant difference in plant height between WT and transgenic plants cultivated in normal conditions. In contrast, Li et al. (2015) and Tian et al. (2017) (2017) found that the overexpression of OsWRKY7O and OsWRKY53 respectively in transgenic rice led to a severe reduction in plant height.

Furthermore, the $V v W R K Y 2$ overexpression resulted in the increase of the plants' compound leaf number in comparison to WT plants under greenhouse culture conditions while no significant difference was observed in plants cultivated in the field (Fig. 2b). The VvWRKY2 transgenic plants exhibited higher stem diameter and leaf area in comparison to WT. These results corroborate those of Freitas-Lima et al. (2017) who reported that transgenic plants overexpressing WRKYTF exhibited increased biomass. These data suggest that $V V W R K Y 2$ TFs are involved in the plant growth and biomass production. These data confirm the fact that $V_{V} W R K Y 2$ overexpressing plants seem to be more vigorous than the WT in greenhouse (Fig. 4a) and field cultures (Fig. 4b). The $V_{V} W R K Y 2$ overexpressing plants showed a distinct foliar shape in comparison to the WT leaves. Indeed, the transgenic plants displayed longer leaf petioles in regards to the WT leaves either in the greenhouse or in the field. Similarly, Tian et al. (2017) showed that the overexpression of OsWRKY53 led to an enlarged angle and modified architecture of rice leaves. These authors suggest that this leaf enlargement seems to be linked to the involvement of OsWRKY53 TF in the brassinosteroid signaling. Accordingly, we can hypothesize that the $V v W R K Y 2$ TF may be involved in the brassinosteroid signaling pathways in potato plants. The leaf area is one of the leading contenders when plant robustness is considered. This parameter is often positively correlated with leaf net photosynthetic rate (Shipley and Lechowicz 2000). Moreover, the increase in the leaf size is bound to plant relative growth rate (Poorter and Remkes 1990) and productivity (Koester et al. 2014). The VvWRKY2 transgenic plants showed significantly higher stomatal conductance than the WT plants, in both greenhouse and in field culture. This result suggests that $V v W R K Y 2$ TF may be involved in the promotion of gas exchange 
parameters and in the stomatal opening and closure. In the same context, Finatto et al. (2018) suggested that WRKYTFs may be involved in stomata closing in response to biotic and abiotic stresses via the ABA regulation pathway.

Similar chlorophyll contents were measured in the leaves of $V v W R K Y 2$ transgenic and WT potato plants. These findings suggest that the VVWRKY2TF is not involved in chlorophyll biosynthesis pathway. Our results are in agreement with those of Guo et al. (2019) who reported that no significant differences were noticed in chlorophyll content between WRKY transgenic plants and WT under normal conditions. These results suggest that the $V v W R K Y 2 \mathrm{TF}$ are not involved in the regulation of chlorophyll biosynthesis or metabolism under non-stressed conditions.

The key objective of the present work was to evaluate the impact of the overexpression of $V v W R K Y 2 \mathrm{TF}$ on the productivity of potato plants under non-stressed conditions. Our data showed that in the greenhouse, the VVWRKY2 transgenic plants produced a higher number of tubers than the WT, while in the field, this parameter was higher in WT in regards to transgenic plants. Interestingly, the tuber weight per plant was significantly higher in $V V W R K Y 2$ transgenic plants than WT both in greenhouse and field cultures. These data suggest that the $V v W R K Y 2 \mathrm{TF}$ overexpression had a positive effect on tuber development. Similarly, the tuber caliber (based on tuber length) and the number of tuber eyes of the VVWRKY2 transgenic plants was higher in comparison to WT. These data corroborated those of Tian et al. (2017) who reported that transgenic rice overexpressing the OsWRKY53 TF displayed higher grain length and width than WT. Raineri et al.(2015) showed also that the HaWRKY76 overexpression in sunflower increased plant biomass and seed yield. Moreover, our results showed a significant impairment of the yellow color of the tuber color between the $V_{V} W R K Y 2$ and WT. These data confirm the important role of WRKY TFs in the regulation of secondary metabolites production pathways (Schluttenhofer and Yuan 2015). A number of studies revealed the involvement of WRKY TFs in the regulation of the production of several secondary metabolites such as phenolic compounds, lignin, flavanols and tannins (review in Phukan et al. 2016).

In potato processing industries, the most important parameter is tuber quality which includes biological, sensorial, and industrial traits (Kumari et al. 2018a). Hence, the composition of potatoes is a very important parameter defining their potential use in food (Gravoueille, 1996; Pedreschi et al. 2012). An analysis of the chemical composition of tubers indicated that the transgenic plants produced tubers with higher dry matter, starch, ash, and minerals but markedly lower lipid and reducing sugar content in comparison to the WT tubers. In fact, low reducing sugar concentration reduces the browning of French fries (Gravoueille, 1996). Tuber dry matter and starch contents are crucial factors for the production of French fries and potato chips (De Freitas et al. 2012; Leonel et al. 2017).

The increase of the dry matter and starch content, the decrease of the reducing sugar content in $V_{V} W R K Y 2$ transgenic plants constitute key parameters that influence the nutritional and industrial properties of potatoes (Kumari et al. 2018b). In fact, the non-enzymatic browning related to high levels of reducing sugars is a serious problem in potato French fries, flakes, and potato chips since it leads to the 
dark color of the end products (Marwaha et al. 2008). These data suggest that VvWRKY2 TF overexpressed in potato plants positively regulated the tuber industrial and nutritional qualities, by increasing dry matter, starch and mineral uptake and lowering the reducing sugar contents.

\section{Conclusions}

Potato is a sensitive plant and its productivity is altered by biotic and abiotic stresses. The overexpression of $V v W R K Y 2 T F$ in potato plants improved the plant vigor, tuber yields, size and the nutritional quality in comparison to the WT. Taken together, our data suggest that $V_{v} W R K Y 2$ would be a good candidate not only for the improvement of potato culture under biotic and abiotic stresses, but also a candidate to promote potato's agricultural performance under non-stress conditions.

\section{Declarations}

The authors declare that they have no known competing financial interests or personal relationships that could have appeared to influence the reported results of this paper.

\section{Acknowledgement:}

Funding for the research was provided by the Tunisian Ministry of High Education and Scientific Research.

\section{Author Contributions}

Chiab.N performed the experiments, statistical analysis, and wrote the manuscript. Kammoun.M and Charfeddine.M helped in the experiments and Gargouri-Bouzid.R revised and approved the manuscript.

\section{Funding}

This research did not receive any specific grant from funding agencies in the public, commercial, or notfor-profit sectors.

\section{Conflicts of Interest}

The authors declare no conflict of interest.

\section{References}

1. AFNOR (1982) Recueil de normes françaises des produits dérivés des fruits et légumes, jus de fruits (Livre, 1982) [WorldCat.org]. https://www.worldcat.org/title/recueil-de-normes-francaises-desproduits-derives-des-fruits-et-legumes-jus-de-fruits/oclc/27325878.

2. Agarwal PK, Gupta K, Lopato S, Agarwal P (2017) Dehydration responsive element binding transcription factors and their applications for the engineering of stress tolerance. Journal of 
Experimental Botany 68, 2135-2148. doi:10.1093/jxb/erx118.

3. Asai T, Tena G, Plotnikova J, Willmann MR, Chiu W-L, Gomez-Gomez L, Boller T, Ausubel FM, Sheen J (2002) MAP kinase signalling cascade in Arabidopsis innate immunity. Nature 415, 977-983. doi:10.1038/415977a.

4. Ayadi M, Hanana M, Kharrat N, Merchaoui H, Benmarzoug R, Lauvergeat V, Rebai A, Mzid R (2016) The WRKY Transcription Factor Family in Citrus: Valuable and Useful Candidate Genes for Citrus Breeding. Applied Biochemistry and Biotechnology 180,. doi:10.1007/s12010-016-2114-8.

5. Ayadi M, Mzid R, Ayed RB, Kharrat N, Merchaoui H, Rebai A, Hanana M (2019) Genome-wide identification and molecular characterization of Citrus unshiu WRKY transcription factors in Satsuma mandarin: clues for putative involvement in cell growth, fruit ripening, and stress response. TURKISH JOURNAL OF AGRICULTURE AND FORESTRY 43, 209-231.

6. Bai Y, Sunarti S, Kissoudis C, Visser RGF, van der Linden CG (2018) The Role of Tomato WRKY Genes in Plant Responses to Combined Abiotic and Biotic Stresses. Frontiers in Plant Science $\mathbf{9}$. doi:10.3389/fpls.2018.00801.

7. Beals KA (2019) Potatoes, Nutrition and Health. American Journal of Potato Research 96, 102-110. doi:10.1007/s12230-018-09705-4.

8. Chacón-Cerdas R, Barboza-Barquero L, Albertazzi FJ, Rivera-Méndez W (2020) Transcription factors controlling biotic stress response in potato plants. Physiological and Molecular Plant Pathology 112, 101527. doi:10.1016/j.pmpp.2020.101527.

9. Chen X, Li C, Wang H, Guo Z (2019) WRKY transcription factors: evolution, binding, and action. Phytopathology Research 1, 1-15. doi:10.1186/s42483-019-0022-x.

10. Chen L, Song Y, Li S, Zhang L, Zou C, Yu D (2012) The role of WRKY transcription factors in plant abiotic stresses. Biochimica Et Biophysica Acta 1819, 120-128. doi:10.1016/j.bbagrm.2011.09.002.

11. Dahal K, Li X-Q, Tai H, Creelman A, Bizimungu B (2019) Improving Potato Stress Tolerance and Tuber Yield Under a Climate Change Scenario - A Current Overview. Frontiers in Plant Science 10, doi:10.3389/fpls.2019.00563.

12. De Freitas S, Pereira E, Silveira Gómez A, Brackmann A, Nicoloso F, Bisognin D (2012) Processing quality of potato tubers produced during autumn and spring and stored at different temperatures. Horticultura Brasileira 30,. doi:10.1590/S0102-05362012000100016.

13. Dellaporta SL, Wood J, Hicks JB (1983) A plant DNA minipreparation: Version II. Plant Molecular Biology Reporter 1, 19-21. doi:10.1007/BF02712670.

14. Eulgem T, Rushton PJ, Robatzek S, Somssich IE (2000) The WRKY superfamily of plant transcription factors. Trends in Plant Science 5, 199-206. doi:10.1016/s1360-1385(00)01600-9.

15. FAO (2019) FAOSTAT. http://www.fao.org/faostat/en/\#data. http://www.fao.org/faostat/en/\#data.

16. Finatto T, Viana VE, Woyann LG, Busanello C, Maia LC da, Oliveira AC de (2018) Can WRKY transcription factors help plants to overcome environmental challenges? Genetics and Molecular Biology 41, 533. doi:10.1590/1678-4685-GMB-2017-0232. 
17. Freitas Lima M de, Nubia Barbosa E, João Antonio Batista de Siqueira, Paulo Cavalcanti Gomes $F$ (2017) Molecular mechanisms of biomass increase in plants. Biotechnology Research and Innovation 1, 14-25. doi:10.1016/j.biori.2017.08.001.

18. Gargouri-Bouzid R (Ecole N d' I de S, Jaoua L (Institut N de la recherche S de T, Mansour RB (Centre de B de S, Hathat Y (Centre de B de S, Ayadi M (Centre de B de S, Ellouz R (Centre de B de S (2005) PVY Resistant Transgenic Potato Plants (cv Claustar) Expressing the Viral Coat Protein. Journal of Plant Biotechnology. https://agris.fao.org/agris-search/search.do?recordID=KR2006015396.

19. Ghislain M, Douches DS (2020) The Genes and Genomes of the Potato. 'The Potato Crop: Its Agricultural, Nutritional and Social Contribution to Humankind'. (Eds H Campos, O Ortiz) pp. 139162. (Springer International Publishing: Cham) doi:10.1007/978-3-030-28683-5_5.

20. Guo Y, Ping W, Chen J, Zhu L, Zhao Y, Guo J, Huang Y (2019) Meta-analysis of the effects of overexpression of WRKY transcription factors on plant responses to drought stress. BMC Genetics 20, 63. doi:10.1186/s12863-019-0766-4.

21. lida K, Seki M, Sakurai T, Satou M, Akiyama K, Toyoda T, Konagaya A, Shinozaki K (2005) RARTF: database and tools for complete sets of Arabidopsis transcription factors. DNA research: an international journal for rapid publication of reports on genes and genomes 12, 247-256. doi:10.1093/dnares/dsi011.

22. Jiang J, Ma S, Ye N, Jiang M, Cao J, Zhang J (2017) WRKY transcription factors in plant responses to stresses. Journal of Integrative Plant Biology 59, 86-101. doi:https://doi.org/10.1111/jipb.12513.

23. Koester RP, Skoneczka JA, Cary TR, Diers BW, Ainsworth EA (2014) Historical gains in soybean (Glycine max Merr.) seed yield are driven by linear increases in light interception, energy conversion, and partitioning efficiencies. Journal of Experimental Botany 65, 3311-3321. doi:10.1093/jxb/eru187.

24. Kumari M, Kumar M, Solankey SS (2018a) Breeding Potato for Quality Improvement. Potato - From Incas to All Over the World. doi:10.5772/intechopen.71482.

25. Kumari M, Kumar M, Solankey SS (2018b) Breeding Potato for Quality Improvement. Potato - From Incas to All Over the World. doi:10.5772/intechopen.71482.

26. Leonel M, do Carmo EL, Fernandes AM, Soratto RP, Ebúrneo JAM, Garcia ÉL, Dos Santos TPR (2017) Chemical composition of potato tubers: the effect of cultivars and growth conditions. Journal of Food Science and Technology 54, 2372-2378. doi:10.1007/s13197-017-2677-6.

27. Li J, Liu J, Wang G, Cha J-Y, Li G, Chen S, Li Z, Guo J, Zhang C, Yang Y, Kim W-Y, Yun D-J, Schumaker KS, Chen Z, Guo Y (2015) A chaperone function of NO CATALASE ACTIVITY1 is required to maintain catalase activity and for multiple stress responses in Arabidopsis. The Plant Cel/ 27, 908-925. doi:10.1105/tpc.114.135095.

28. Li S, Nayar S, Jia H, Kapoor S, Wu J, Yukawa Y (2020) The Arabidopsis Hypoxia Inducible AtR8 Long Non-Coding RNA also Contributes to Plant Defense and Root Elongation Coordinating with WRKY Genes under Low Levels of Salicylic Acid. Non-Coding RNA 6, 8. doi:10.3390/ncrna6010008. 
29. Li M-Y, Xu Z-S, Tian C, Huang Y, Wang F, Xiong A-S (2016) Genomic identification of WRKY transcription factors in carrot ( Daucus carota) and analysis of evolution and homologous groups for plants. Scientific Reports 6, 1-17. doi:10.1038/srep23101.

30. Li J-W, Zhang X-Y, Wu H, Bai Y-P (2020) Transcription Factor Engineering for High-Throughput Strain Evolution and Organic Acid Bioproduction: A Review. Frontiers in Bioengineering and Biotechnology 8. doi:10.3389/fbioe.2020.00098.

31. Marchive C, Mzid R, L D, F B, J P, A G, Mf C-C, F R, B C, S H, V L (2007) Isolation and characterization of a Vitis vinifera transcription factor, VvWRKY1, and its effect on responses to fungal pathogens in transgenic tobacco plants. Journal of experimental botany 58,. doi:10.1093/jxb/erm062.

32. Marwaha R S, Kumar D, Singh S, Pandey S K (2008) Influence of blanching of slices of potato varieties on chipping quality | Request PDF. ResearchGate 45, 364-367.

33. Miller GL (1959) Use of Dinitrosalicylic Acid Reagent for Determination of Reducing Sugar. Analytical Chemistry. doi:10.1021/ac60147a030.

34. Morel G, Wetmore RH (1951) Tissue Culture of Monocotyledons. American Journal of Botany 38, 138-140. doi:10.1002/j.1537-2197.1951.tb14803.x.

35. Murashige T, Skoog F (1962) A Revised Medium for Rapid Growth and Bio Assays with Tobacco Tissue Cultures. Physiologia Plantarum 15, 473-497. doi:10.1111/j.1399-3054.1962.tb08052.x.

36. Mzid R, Marchive C, D B, L D, F B, Mf C-C, N D, S H, V L (2007) Overexpression of VvWRKY2 in tobacco enhances broad resistance to necrotrophic fungal pathogens. Physiologia Plantarum 131, 434-447. doi:10.1111/j.1399-3054.2007.00975.x.

37. Mzid R, Zorrig W, Ben Ayed R, Ben Hamed K, Ayadi M, Damak Y, Lauvergeat V, Hanana M (2018) The grapevine VvWRKY2 gene enhances salt and osmotic stress tolerance in transgenic Nicotiana tabacum. 3 Biotech 8, 277. doi:10.1007/s13205-018-1301-4.

38. Nozeran R, Rossignol-Bancilhon L (1977) La multiplication végétative chez les végétaux vasculaires. Bulletin de la Société Botanique de France 124, 59-96. doi:10.1080/00378941.1977.10839412.

39. Pandey SK, Singh H (2011) A Simple, Cost-Effective Method for Leaf Area Estimation. Journal of Botany 2011.doi:10.1155/2011/658240.

40. Pedreschi F, Bunger Timmermann A, Skurtys O, Allen P, Rojas X (2012) Grading of Potato Chips According to Their Sensory Quality Determined by Color. Food and Bioprocess Technology. doi:10.1007/s11947-011-0559-x.

41. Phukan UJ, Jeena GS, Shukla RK (2016) WRKY Transcription Factors: Molecular Regulation and Stress Responses in Plants. Frontiers in Plant Science 7,. doi:10.3389/fpls.2016.00760.

42. Poorter $H$, Remkes $C$ (1990) Leaf area ratio and net assimilation rate of 24 wild species differing in relative growth rate. Oecologia $\mathbf{8 3}, 553-559$. doi:10.1007/BF00317209.

43. Qin Y, Tian Y, Liu X (2015) A wheat salinity-induced WRKY transcription factor TaWRKY93 confers multiple abiotic stress tolerance in Arabidopsis thaliana. Biochemical and Biophysical Research Communications 464, 428-433. doi:10.1016/j.bbrc.2015.06.128. 
44. Qiu D, Xiao J, Ding X, Xiong M, Cai M, Cao Y, Li X, Xu C, Wang S (2007) OsWRKY13 mediates rice disease resistance by regulating defense-related genes in salicylate- and jasmonate-dependent signaling. Molecular plant-microbe interactions: MPMI 20, 492-499. doi:10.1094/MPMI-20-5-0492.

45. Raineri J, Ribichich KF, Chan RL (2015) The sunflower transcription factor HaWRKY76 confers drought and flood tolerance to Arabidopsis thaliana plants without yield penalty. Plant Cell Reports 34, 2065-2080. doi:10.1007/s00299-015-1852-3.

46. Rogan GJ, Bookout JT, Duncan DR, Fuchs RL, Lavrik PB, Love SL, Mueth M, Olson T, Owens ED, Raymond PJ, Zalewski J (2000) Compositional Analysis of Tubers from Insect and Virus Resistant Potato Plants. Journal of Agricultural and Food Chemistry 48, 5936-5945. doi:10.1021/jf000742b.

47. Rushton PJ, Somssich IE, Ringler P, Shen QJ (2010) WRKY transcription factors. Trends in Plant Science 15, 247-258. doi:10.1016/j.tplants.2010.02.006.

48. Saïdi MN, Gargouri-Bouzid R, Rayanni M, Drira N (2009) Optimization of RNA isolation from Brittle Leaf Disease affected date palm leaves and construction of a subtractive cDNA library. Molecular Biotechnology 41, 63-68. doi:10.1007/s12033-008-9104-1.

49. Schluttenhofer C, Yuan L (2015) Regulation of Specialized Metabolism by WRKY Transcription Factors. Plant Physiology 167, 295-306. doi:10.1104/pp.114.251769.

50. Shinozaki Y, Hao S, Kojima M, Sakakibara H, Ozeki-lida Y, Zheng Y, Fei Z, Zhong S, Giovannoni JJ, Rose JKC, Okabe Y, Heta Y, Ezura H, Ariizumi T (2015) Ethylene suppresses tomato (Solanum lycopersicum) fruit set through modification of gibberellin metabolism. The Plant Journal: For Cell and Molecular Biology 83, 237-251. doi:10.1111/tpj.12882.

51. Shipley B, Lechowicz MJ (2000) The functional co-ordination of leaf morphology, nitrogen concentration, and gas exchange in 40 wetland species. Écoscience 7, 183-194. doi:10.1080/11956860.2000.11682587.

52. Singh K, Foley RC, Oñate-Sánchez L (2002) Transcription factors in plant defense and stress responses. Current Opinion in Plant Biology 5, 430-436. doi:10.1016/s1369-5266(02)00289-3.

53. Tian X, Li X, Zhou W, Ren Y, Wang Z, Liu Z, Tang J, Tong H, Fang J, Bu Q (2017) Transcription Factor OsWRKY53 Positively Regulates Brassinosteroid Signaling and Plant Architecture. Plant Physiology 175, 1337-1349. doi:10.1104/pp.17.00946.

54. Tuteja N (2007) Mechanisms of high salinity tolerance in plants. Methods in Enzymology 428, 419438. doi:10.1016/S0076-6879(07)28024-3.

55. Ulker B, Somssich IE (2004) WRKY transcription factors: from DNA binding towards biological function. Current Opinion in Plant Biology 7, 491-498. doi:10.1016/j.pbi.2004.07.012.

56. Verwoerd TC, Dekker BM, Hoekema A (1989) A small-scale procedure for the rapid isolation of plant RNAs. Nucleic Acids Research 17, 2362.

57. Xie Z, Zhang Z-L, Zou X, Huang J, Ruas P, Thompson D, Shen QJ (2005) Annotations and Functional Analyses of the Rice WRKY Gene Superfamily Reveal Positive and Negative Regulators of Abscisic Acid Signaling in Aleurone Cells. Plant Physiology 137, 176-189. doi:10.1104/pp.104.054312. 
58. Xiong Y, Liu T, Tian C, Sun S, Li J, Chen M (2005) Transcription Factors in Rice: A Genome-wide Comparative Analysis between Monocots and Eudicots. Plant Molecular Biology 59, 191-203. doi:10.1007/s11103-005-6503-6.

59. Yan J, Wang B, Zhong Y, Yao L, Cheng L, Wu T (2015) The soybean R2R3 MYB transcription factor GmMYB100 negatively regulates plant flavonoid biosynthesis. Plant Molecular Biology 89, 35-48. doi:10.1007/s11103-015-0349-3.

60. Yao D-M, Zou C, Shu Y-N, Liu S-S (2020) WRKY Transcription Factors in Nicotiana tabacum Modulate Plant Immunity against Whitefly via Interacting with MAPK Cascade Pathways. Insects 12, 16. doi:10.3390/insects12010016.

61. Zhu D, Che Y, Xiao P, Hou L, Guo Y, Liu X (2018) Functional analysis of a grape WRKY30 gene in drought resistance. Plant Cell, Tissue and Organ Culture (PCTOC) 132, 449-459. doi:10.1007/s11240-017-1341-1.

62. Zhu Z, Li Y-S, Feng, Ren J (2020) StABI5 Involved in the Regulation of Chloroplast Development and Photosynthesis in Potato. International Journal of Molecular Sciences 21, 1068. doi:10.3390/ijms21031068.

63. Zou X, Seemann JR, Neuman D, Shen QJ (2004) A WRKY Gene from Creosote Bush Encodes an Activator of the Abscisic Acid Signaling Pathway *. Journal of Biological Chemistry 279, $55770-$ 55779. doi:10.1074/jbc.M408536200.

\section{Tables}

Table 1: Tuber yields, caliber, number of eyes of the WT and the VvWRKY2 overexpressing plants in greenhouse and in field. 


\begin{tabular}{|c|c|c|c|c|c|}
\hline & & \multicolumn{2}{|l|}{ Greenhouse } & \multicolumn{2}{|l|}{ Field } \\
\hline & & WT & VVWRKY2 & WT & VVWRKY2 \\
\hline \multirow[t]{2}{*}{ Yields } & Number of tubers/plant & $0.86^{a} \pm 0.49$ & $\begin{array}{l}1.05^{\mathrm{b}} \pm \\
0.02\end{array}$ & $4.62^{\mathrm{a}} \pm 0.18$ & $3.2^{b} \pm 0.28$ \\
\hline & $\begin{array}{l}\text { Weight of tubers/plant } \\
\text { (g) }\end{array}$ & $0.41^{\mathrm{a}} \pm 0.1$ & $\begin{array}{l}1.91^{\mathrm{b}} \pm \\
0.25\end{array}$ & $64.12^{\mathrm{a}} \pm 2.3$ & $72.5^{\mathrm{b}} \pm 3.53$ \\
\hline \multirow{3}{*}{$\begin{array}{l}\text { Caliber } \\
\text { (\%) }\end{array}$} & $<1.5$ & $43.11^{\mathrm{a}} \pm 0.74$ & $\begin{array}{l}37.5^{b} \pm \\
0.03\end{array}$ & $\begin{array}{l}32.43^{\mathrm{a}} \pm \\
0.64\end{array}$ & $\begin{array}{l}11.42^{b} \pm \\
0.07\end{array}$ \\
\hline & {$[1.5-3 \mathrm{~cm}]$} & $52.8^{a} \pm 1.68$ & $\begin{array}{l}62.5^{b} \pm \\
0.03\end{array}$ & $\begin{array}{l}29.72^{\mathrm{a}} \pm \\
1.52\end{array}$ & $\begin{array}{l}34.28^{\mathrm{b}} \pm \\
0.22\end{array}$ \\
\hline & [3- $4.5 \mathrm{~cm}]$ & 0 & 0 & $\begin{array}{l}37.83^{\mathrm{a}} \pm \\
0.67\end{array}$ & $54.28^{\mathrm{b}} \pm 0.2$ \\
\hline \multicolumn{2}{|c|}{ Number of eyes/tuber } & $0.23^{2.47^{\mathrm{a}} \pm}$ & $\begin{array}{l}3.27^{b} \pm \\
0.21\end{array}$ & $3.35^{a} \pm 0.31$ & $4.18^{b} \pm 0.04$ \\
\hline
\end{tabular}

Data represent means \pm standard deviation ( $n=3$ ), all values with superscripts (a-b) are significantly different (at $P \leq 0.05$, ANOVA test). Statistical differences were evaluated between the WT and VvWRKY2 separately in greenhouse and in field.

Table 2: Chemical composition of the WT and the VvWRKY2 overexpressing tubers generated from greenhouse and field culture. 


\begin{tabular}{|lllll|}
\hline & Greenhouse & & Field & \\
\hline Parameters & WT & V vWRKY2 & WT & V WWRKY2 \\
\hline Dry matter (\%) & $17.62^{\mathrm{a}} \pm 0.55$ & $19.40^{\mathrm{b}} \pm 1.35$ & $19.35^{\mathrm{a}} \pm 0.55$ & $21.19^{\mathrm{b}} \pm 0.36$ \\
\hline Starch (\%) & $9.79^{\mathrm{a}} \pm 0.69$ & $13.88^{\mathrm{b}} \pm 0.57$ & $20.28^{\mathrm{a}} \pm 1.86$ & $22.84^{\mathrm{a}} \pm 1.09$ \\
\hline Reducing sugar (\%) & $1.71^{\mathrm{a}} \pm 0.04$ & $0.48^{\mathrm{b}} \pm 0.038$ & $0.88^{\mathrm{a}} \pm 0.1$ & $0.57^{\mathrm{b}} \pm 0.02$ \\
\hline Lipids (\%) & $0.43^{\mathrm{a}} \pm 0.02$ & $0.28^{\mathrm{b}} \pm 0.02$ & $0.28^{\mathrm{a}} \pm 0.09$ & $0.26^{\mathrm{a}} \pm 0.02$ \\
\hline Ashs (\%) & $1.14^{\mathrm{a}} \pm 0.001$ & $1.62^{\mathrm{a}} \pm 0.082$ & $1.63^{\mathrm{a}} \pm 0.6$ & $1.67^{\mathrm{a}} \pm 0.08$ \\
\hline Minerals (mg/g) & & & & \\
\hline \multicolumn{1}{|c|}{$\mathrm{K}$} & $0.14^{\mathrm{a}} \pm 0.001$ & $0.13^{\mathrm{a}} \pm 0.007$ & $0.704^{\mathrm{a}} \pm 0.66$ & $1.906^{\mathrm{b}} \pm 0.17$ \\
\hline Mg & $0.013^{\mathrm{a}} \pm 0.006$ & $0.080^{\mathrm{a}} \pm 0.004$ & $0.67^{\mathrm{a}} \pm 0.08$ & $0.79^{\mathrm{a}} \pm 0.55$ \\
\hline Fe & $0.0001^{\mathrm{a}} \pm 0$ & $0.0001^{\mathrm{a}} \pm 0$ & $0.023^{\mathrm{a}} \pm 0.02$ & $0.020^{\mathrm{a}} \pm 0.02$ \\
\hline Ca & $0.0713^{\mathrm{a}} \pm 0.039$ & $0.085^{\mathrm{a}} \pm 0.04$ & $0.773^{\mathrm{a}} \pm 0.08$ & $0.939^{\mathrm{a}} \pm 0.01$ \\
\hline Zn & $0.0001^{\mathrm{a}} \pm 0$ & $0.0001^{\mathrm{a}} \pm 0$ & $0^{\mathrm{a}} \pm 0$ & $0.004^{\mathrm{a}} \pm 0$ \\
\hline P & $0.013^{\mathrm{a}} \pm 0.004$ & $0.013^{\mathrm{a}} \pm 0.002$ & $0.008^{\mathrm{a}} \pm 0$ & $0.008^{\mathrm{a}} \pm 0$ \\
\hline
\end{tabular}

Data represent means \pm standard deviation $(n=3)$, all values with superscripts $(a-b)$ are significantly different (at $P \leq 0.05$, ANOVA test). Statistical differences were evaluated between the WT and VVWRKY2 separately in greenhouse and in field.

\section{Figures}

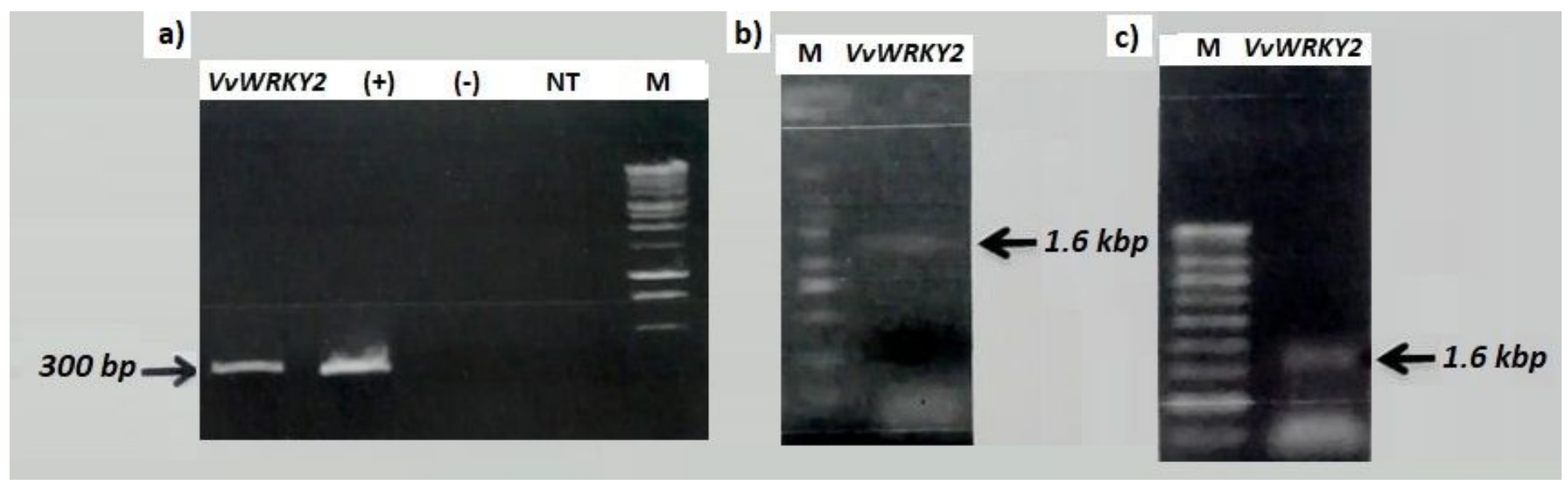

Figure 1 
Molecular identification of WT and transgenic potato plants overexpressing the VvWRKY2 TF: PCR amplification products of the 35S promoter (a) and of the VvWRKY2 cDNA (b). The expression of VvWRKY2 gene resulted from RT-PCR (c). Positive control (MDC32 plasmid containing the PR35S) :(+). Negative control (without DNA) :(-). DNA of non-transformed control:(NT). 1 kb DNA ladder:(M).

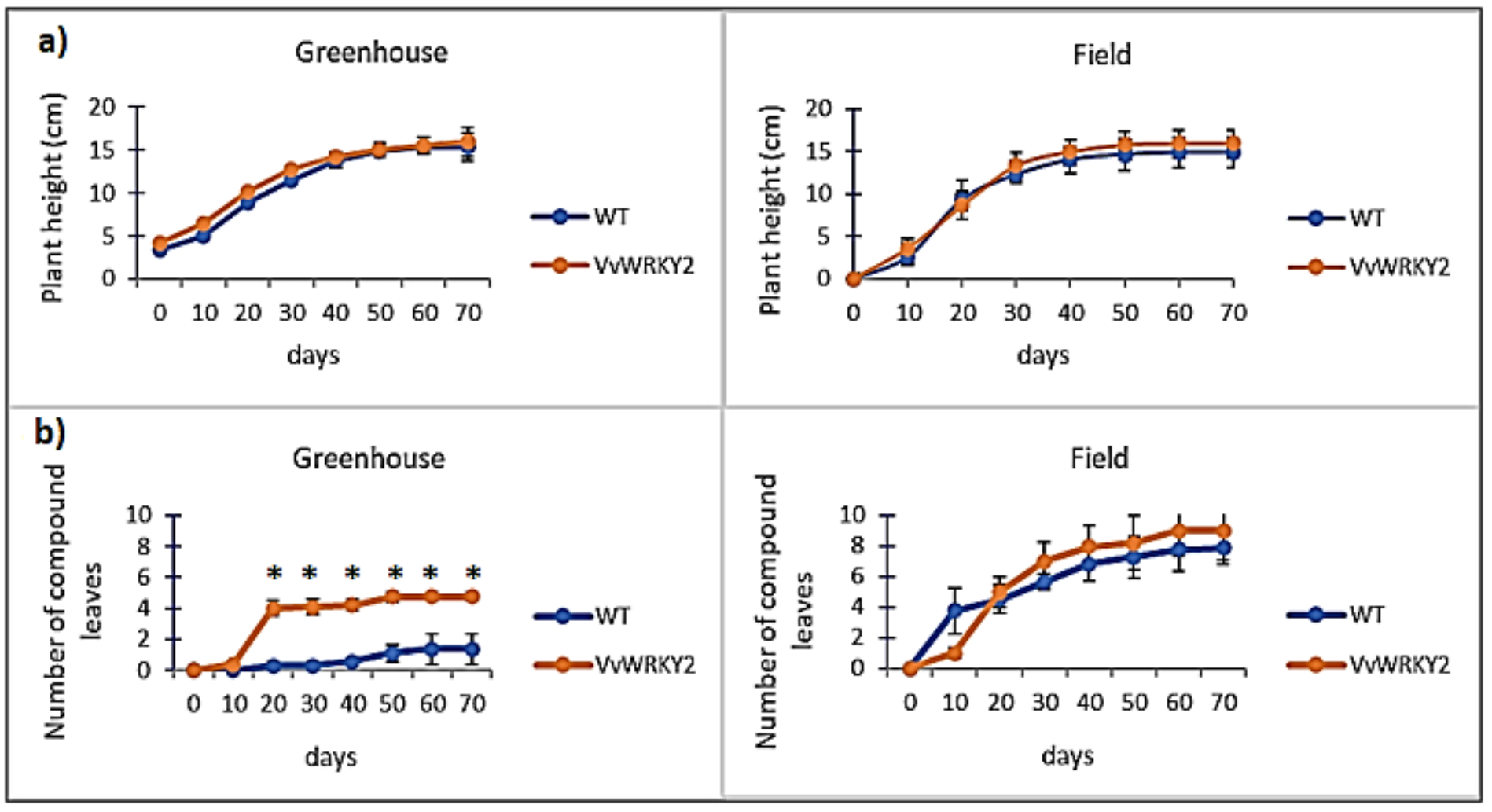

Figure 2

Evaluation of the height of the WT and VvWRKY2 plants (a) and compound leaves number (b) after 60 days of greenhouse and field cultures. Each data represents an average of at least three replicates. Data represent means \pm Standard deviation. Values with Asterix $\left({ }^{*}\right)$ are significantly different at $P<0.05$, ANOVA test.

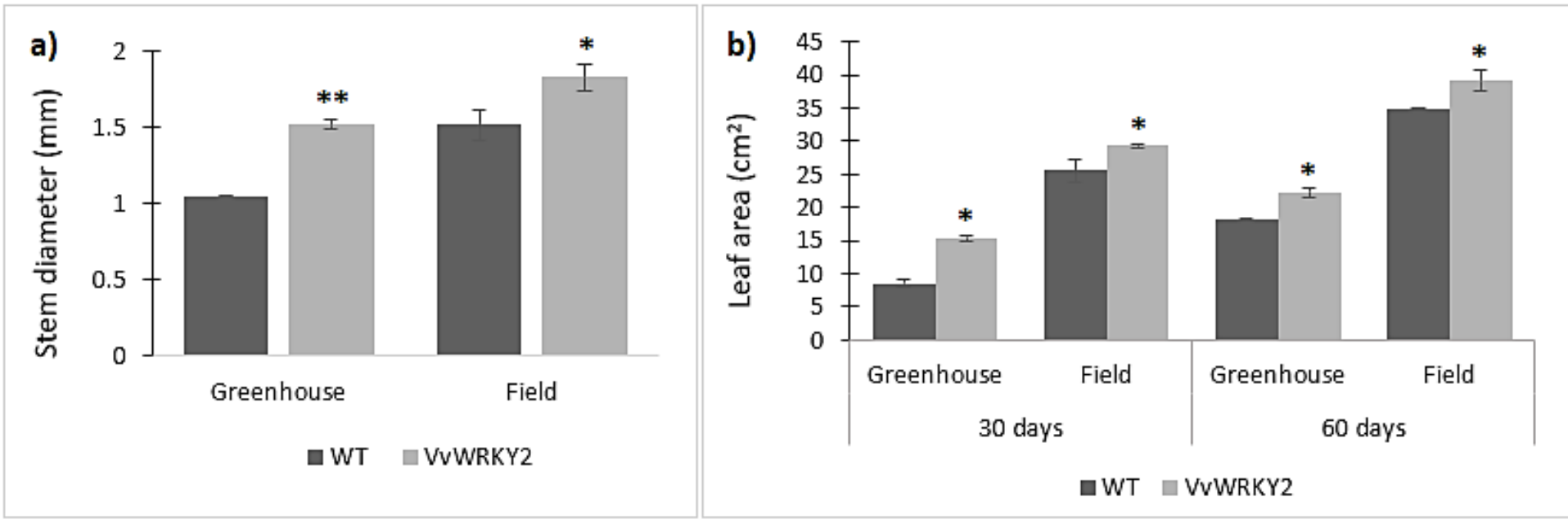

Figure 3 
Assessment of stem diameter after 60 days of greenhouse and field cultures $(\mathrm{mm})(\mathrm{a})$, leaf area $(\mathrm{cm} 2)$ (b) of the WT and VvWRKY2 plants after 60 days of culture in greenhouse and in field. Each data represents an average of at least three independent replicates. Data represent means \pm Standard deviation. Asterisks $\left.{ }^{(*}\right)$ and $(*)$ indicate significant and very significant differences at $\mathrm{P}<0.05$ and $\mathrm{P}<$ 0.01 (ANOVA test), respectively.

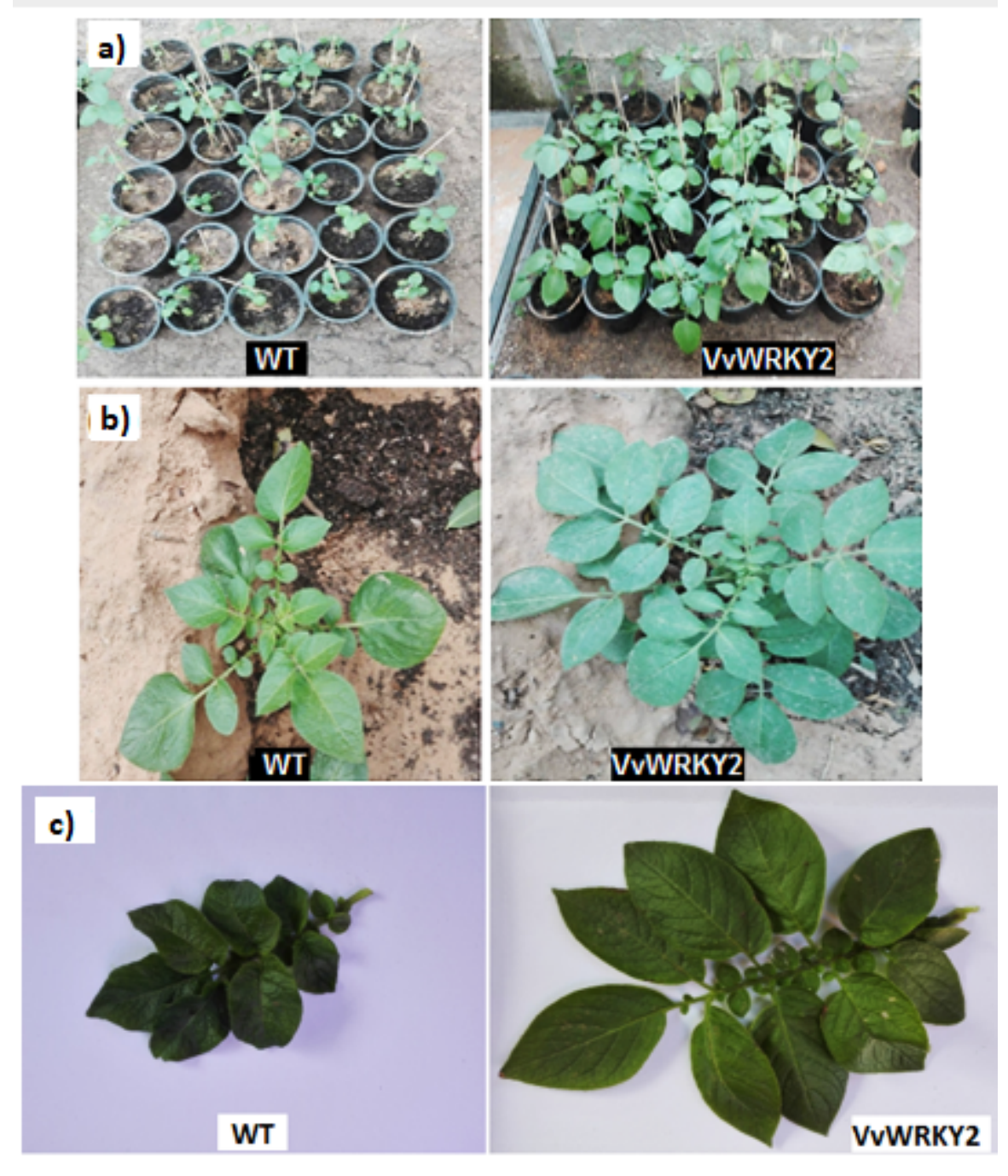

\section{Figure 4}

Morphology of WT and VvWRKY2 plants after 60 days in greenhouse (a) and in field (b). Morphology and shape of a compound leaf after 60 days of field culture (c). 


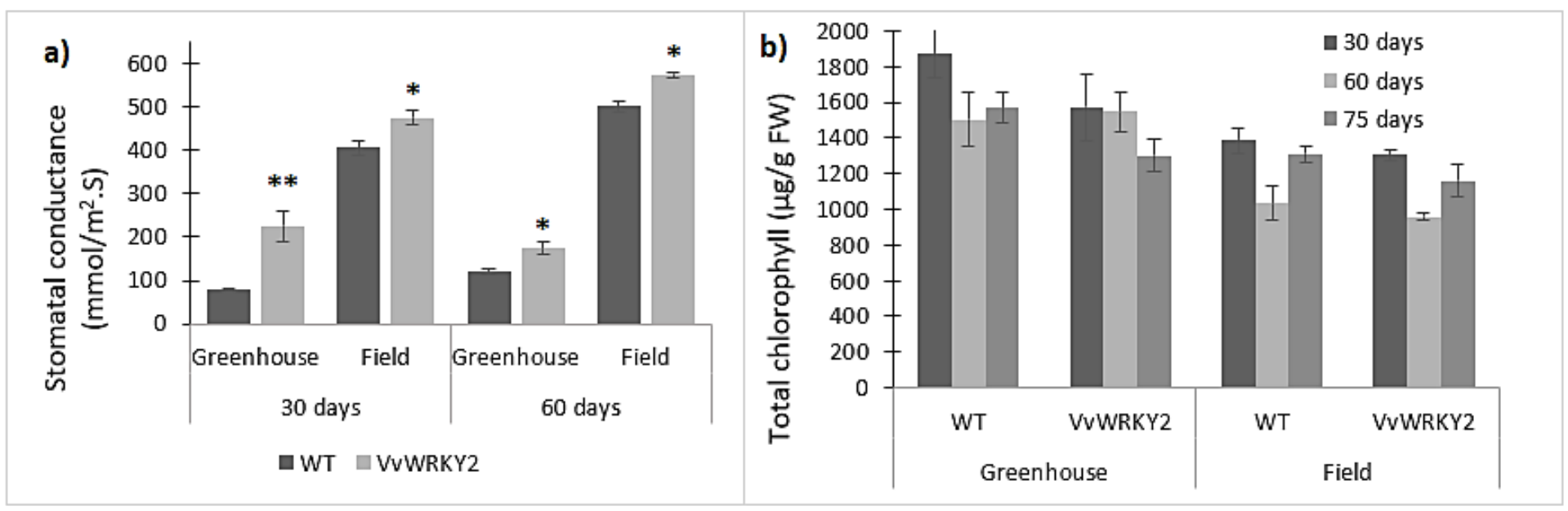

\section{Figure 5}

Evaluation of the stomatal conductance (mmol m-2 S-1) after 30 and 60 days of culture (a) and total chlorophyll content (b) ( $\mu \mathrm{gg}$ FW-1) of WT and VvWRKY2 plants after 30, 60 and 75 days in the greenhouse and in the field (a).

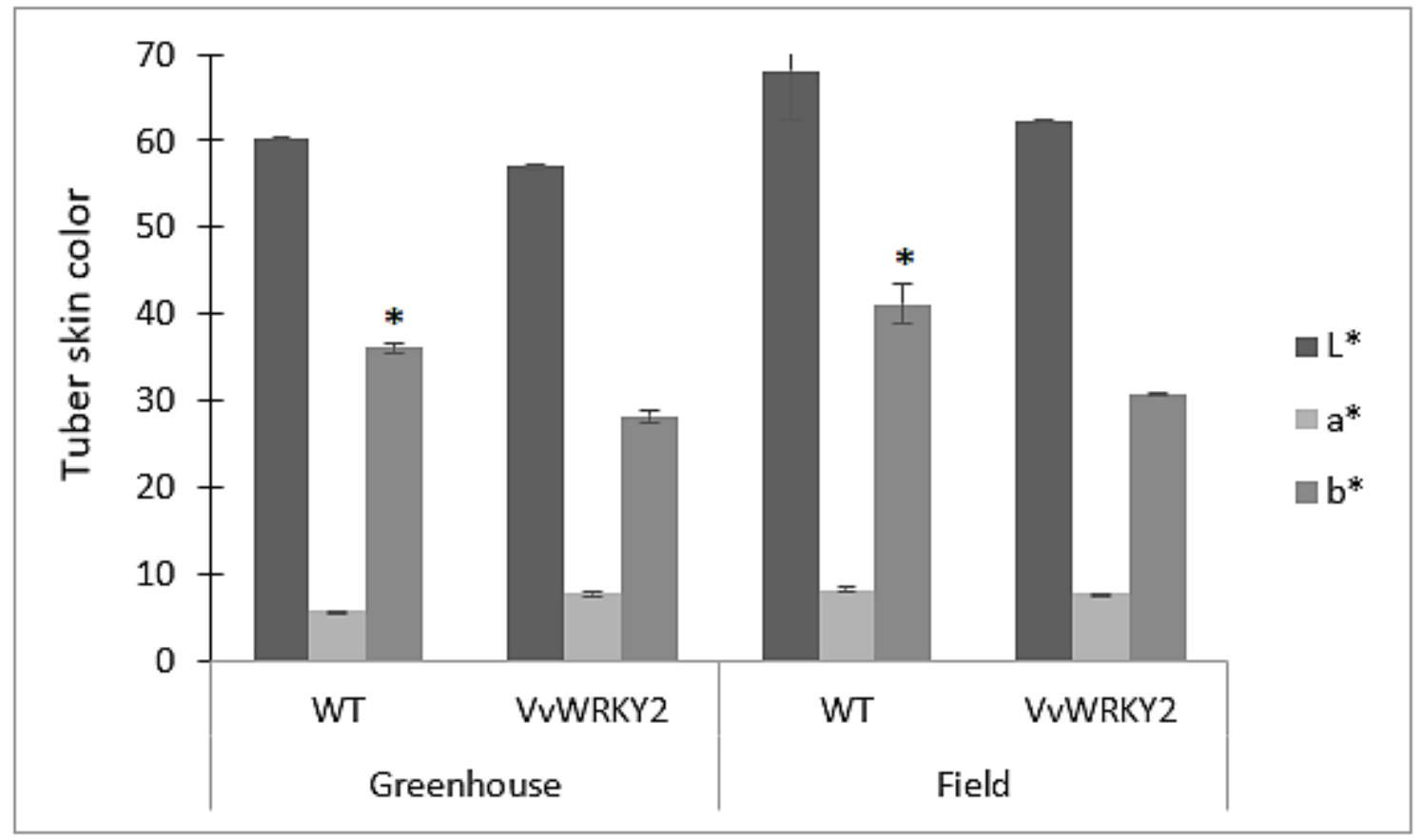

\section{Figure 6}

Measurement of the fields' tubers skin color. L* represents: the clarity index, $a^{\star}$ : chromatic coordinates of red color, and b*: chromatic coordinates of yellow color. All Data are represented by means of three independent repeats \pm standard deviation. Values with $\left(^{*}\right)$ and $\left({ }^{* *}\right)$ indicate significant differences at $P<$ 0.05 and $P<0.01$ (ANOVA test), respectively. 